\title{
VALIDAÇÃO DE FOCOS DE CALOR UTILIZADOS NO MONITORAMENTO ORBITAL DE QUEIMADAS POR MEIO DE IMAGENS TM
}

\author{
Allan Arantes Pereira ${ }^{1}$, José Aldo Alves Pereira ${ }^{2}$, Fabiano Morelli ${ }^{3}$ Dalmo Arantes Barros ${ }^{4}$, \\ Fausto Weimar Acerbi Jr. ${ }^{5}$, José Roberto Soares Scolforo ${ }^{6}$
}

(recebido: 26 de fevereiro de 2010; aceito: 31 de janeiro de 2012)

\begin{abstract}
RESUMO: Este trabalho foi realizado com o objetivo de validar os focos de calor utilizados no monitoramento de queimadas. Para isso, mapearam-se as queimadas ocorridas em seis Unidades de Conservação, localizadas no norte do estado de Minas Gerais, no período de 03 de setembro a 05 de outubro de 2008, por meio da segmentação semiautomática de imagens LandSat 5 TM. Foram mapeadas 190 queimadas e averiguada sua detecção pelos satélites por meio dos focos de calor gerados operacionalmente pelo Instituto Nacional de Pesquisas Espaciais - INPE. Também foram analisadas por classe de tamanho, a fim de verificar qual a influência do tamanho das queimadas na detecção. A análise da distância dos focos aos limites das queimadas foi feita por meio de faixas equidistantes ("buffers"), com incremento de 1,00 km em cada classe até o limite de 9,00 km. Das cicatrizes de queimadas analisadas, aproximadamente $26,00 \%$ foram detectadas, demonstrando limitações do sistema em detectar aquelas menores que 100,00 ha. Apesar dessa limitação, grande parte da área impactada foi detectada, perfazendo um total de acerto de aproximadamente $71,00 \%$. Os resultados de erros de localização foram considerados satisfatórios, tendo em vista as limitações técnicas da resolução espacial dos sensores utilizados. Essas informações geram subsídios ao avanço tecnológico do monitoramento orbital.
\end{abstract}

Palavras-chave: Sensoriamento remoto, incêndios florestais, unidades de conservação.

\section{VALIDATION OF HOTSPOTS UTILIZED IN THE ORBITAL MONITORING OF BURNT AREAS BY MEANS OF TM IMAGES}

\begin{abstract}
This work was conducted with the purpose of validating the hotspots utilized in fire monitoring. The burnt areas observed in six conservation units situated in north of the State of Minas Gerais were mapped in the period of September 3rd to October 5th, 2008, using semi-automatic segmentation of LandSat 5 TM images. A total of 190 burnt areas were mapped and the detections were verified using the satellites hotspots generated by the Brazilian National Space Research Institute - INPE. The burnt areas were also analyzed by size class in order to verify the hypothesis that the smallest areas are less liable to detection. The analysis of the hotspots distance to the limits of the burnt areas was done using buffers, with an increase of $1.00 \mathrm{~km}$ in every class, up to the limit of $9.00 \mathrm{~km}$. Considering the investigated burnt areas, about 26.00\% were detected, demonstrating limitations of the system to detect burnings smaller than $100.00 \mathrm{ha}$. In spite of that limitation, a great portion of the impacted area was detected, reaching a total of hits of about $71.00 \%$. The results of location errors were considered satisfactory, considering the technical limitations of the spatial resolution of the utilized sensors. This information may subside the technological advancement of orbital monitoring.
\end{abstract}

Key words: Remote sensing, forest fires, conservation units.

\section{INTRODUÇÃO}

A necessidade de avançar continuamente no controle às queimadas em ambientes naturais fomenta a produção de tecnologias que possibilitam monitorar suas ocorrências no planeta. Atualmente, análises geradas em sistemas de informações geográficas com dados derivados de sensoriamento remoto propiciam uma ampla visão sobre distribuição temporal, espacial e padrões das queimadas em diferentes escalas, permitindo estudar as interações do fogo com as relações culturais e sócioambientais.

\footnotetext{
${ }^{1}$ Engenheiro Florestal, Professor Mestre em Engenharia Florestal - IFSULDEMINAS - Rua Coronel Virgilio Silva, 1723, Vila Nova - 37701-642 Poços de Caldas, MG, Brasil - allan.pereira@ifsuldeminas.edu.br

${ }^{2}$ Engenheiro Florestal, Professor Doutor em Ecologia - Departamento de Ciências Florestais/DCF - Universidade Federal de Lavras/UFLA - Cx. P. 3037 37200-000 - Lavras, MG, Brasil - j.aldo@dcf.ufla.br

${ }^{3}$ Oceanógrafo, Doutor em Engenharia Aeronáutica e Mecânica - Centro Espacial de Cachoeira Paulista - Instituto Nacional de Pesquisas Espaciais/INPE Rodovia Presidente Dutra, Km 40 - 12630-000 - Cachoeira Paulista, SP, Brasil - fabiano.morelli@cptec.inpe.br

${ }^{4}$ Engenheiro Florestal, Doutorando em Engenharia Florestal - Departamento de Ciências Florestais/DCF - Universidade Federal de Lavras/UFLACx. P. 3037 -37200-000 - Lavras, MG, Brasil - dalmo.barros@uol.com.br

${ }^{5}$ Engenheiro Florestal, Professor Doutorando em Sensoriamento Remoto - Departamento de Ciências Florestais - Universidade Federal de Lavras Cx. P. 3037 -37200-000 - Lavras, MG, Brasil - fausto@dcf.ufla.br

${ }^{6}$ Engenheiro Florestal, Professor Doutor em Engenharia Florestal - Departamento de Ciências Florestais - Universidade Federal de Lavras - Cx. P. 3037 37200-000 - Lavras, MG, Brasil - scolforo@dcf.ufla.br
}

Cerne, Lavras, v. 18, n. 2, p. 335-343, abr./jun. 2012 
A gestão de projetos governamentais com ações operacionais de monitoramento e combate deve ser fundamentada em dados históricos e deteç̧ão de fogos ativos. Esses dados permitem a emissão de alertas de incêndios em períodos de baixa umidade relativa do ar (DEEP; PAULA, 2004; PEREIRA et al., 2007; PHULPIN et al., 2002; XAUD et al., 2003). As informações do monitoramento podem também ser utilizadas em sistemas de fiscalização, prevenção e planejamento estratégico de investimentos, bem como em ações administrativas.

Em Minas Gerais, todas as unidades de conservação Federais e Estaduais são monitoradas quanto à ocorrência de focos de calor, tanto no seu interior, como no entorno (PEREIRA et al., 2007). Ao lado disso, esses dados históricos são utilizados para a determinação de áreas críticas e orientação das atividades de prevenção.

Diante desse cenário, trabalhos de validação auxiliam na utilização desses produtos, permitindo um aperfeiçoamento tecnológico no monitoramento das queimadas (MORISETTE; KHORRAM, 2000), bem como no desenvolvimento de novas tecnologias, garantindo uma maior confiança no planejamento das ações de combate a incêndios florestais.

Este trabalho foi realizado com o objetivo principal de avaliar a possibilidade de utilização de ferramentas da geotecnologia para validação dos focos de calor em
Unidades de Conservação de Minas Gerais, respondendo às seguintes questões: qual a quantidade de queimadas detectadas pelo monitoramento de satélite; qual a influência do tamanho das queimadas na detecção via focos de calor; os possíveis erros de comissão; e quais os erros de localização dos focos em relação às cicatrizes mapeadas.

\section{MATERIAL E MÉTODOS}

\section{1 Área de estudo}

A área escolhida para este estudo, localiza-se na região norte do estado de Minas Gerais, a leste do rio São Francisco, entre as seguintes coordenadas $14^{\circ} 30^{\prime} 00^{\prime \prime}$ a $16^{\circ}$ $00^{\prime} 00^{\prime}$ " de latitude sul e $44^{\circ} 30^{\prime} 00^{\prime \prime}$ a $45^{\circ} 40^{\prime} 00^{\prime \prime}$ longitude oeste. Abrange seis unidades de conservação (UC) estaduais, sendo três pertencentes à categoria de proteção integral: refúgio da vida silvestre (01), parques estaduais (02) e mais três à categoria de uso sustentável: áreas de proteção ambiental (02) e reserva de desenvolvimento sustentável (01). Com exceção das APAs, o estudo compreende, além das próprias áreas das UCs, uma faixa adicional de $5 \mathrm{~km}$ (zona de amortecimento ou buffer), a partir dos perímetros das respectivas UCs, perfazendo uma superfície total aproximada de $9.369,00 \mathrm{~km}^{2}$, o que equivale a $1,60 \%$ de toda a extensão territorial do estado de Minas Gerais (Figura 1).

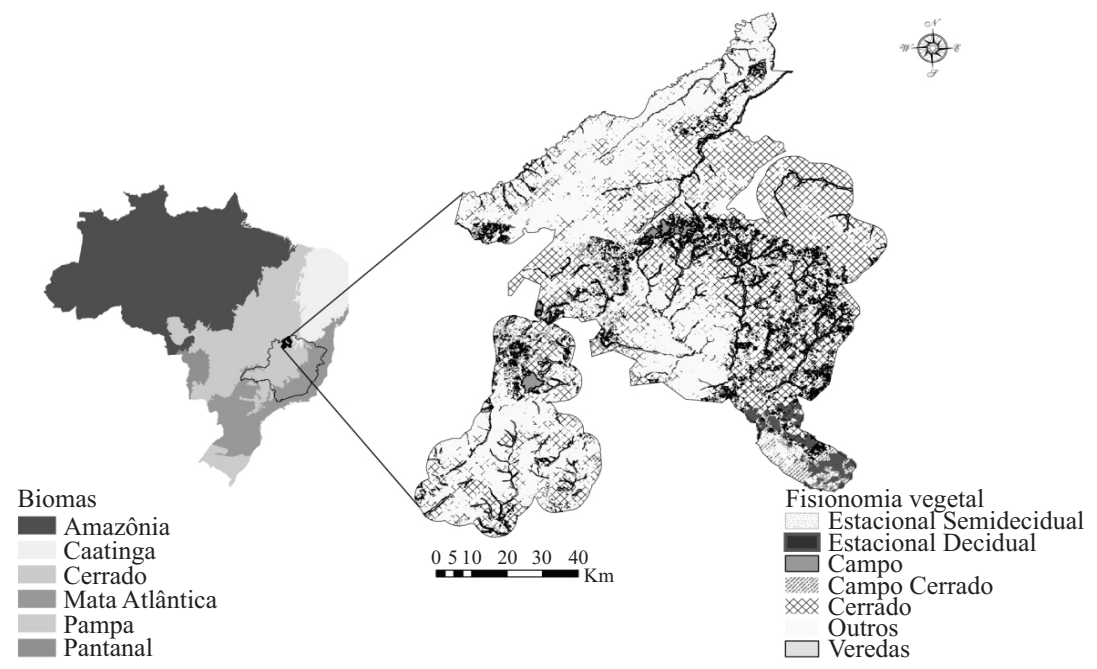

Figura 1 - À esquerda, o mapa de biomas do Brasil (INSTITUTO BRASILEIRO DE GEOGRAFIA E ESTATÍSTICA - IBGE, 2004) e contorno com o limite estadual de Minas Gerais; à direita mapa da fisionomia vegetal na área de estudo: seis unidades de conservação no norte do estado de Minas Gerais (CARVALHO; SCOLFORO, 2008).

Figure 1 - On the left, Brazil's biomas map (INSTITUTO BRASILEIRO DE GEOGRAFIA E ESTATÍSTICA - IBGE, 2004) and boundary with the limit of Minas Gerais State; on the right, the land cover map of the study area: six conservation units (CARVALHO; SCOLFORO, 2008).

Cerne, Lavras, v. 18, n. 2, p. 335-343, abr./jun. 2012 
Como pode ser observado na Figura 1, a vegetação da área de estudo insere-se na transição entre os biomas da Caatinga e Cerrado, com predomínio do Cerrado e suas variações (INSTITUTO DE GEOCIÊNCIA APLICADA IGA, 2006).

O clima da região é classificado, segundo Köeppen (1936), como tropical chuvoso - Awiq, com temperatura de todos os meses superior a $18,00^{\circ} \mathrm{C}$, seca acentuada geralmente nos períodos compreendidos de julho a novembro e chuva anual periódica superior a 750,00 $\mathrm{mm}$.

Utilizando dados obtidos pela estação meteorológica do Colégio Agrícola de Januária, situada a cerca de $20 \mathrm{~km}$ da área de estudo, percebeu-se que no período de 2000 a 2009 o clima regional foi ligeiramente diferente da classificação proposta por Köppen (1936), como pode ser observado na Figura 2, onde o período de menor precipitação foi durante os meses de maio a setembro.

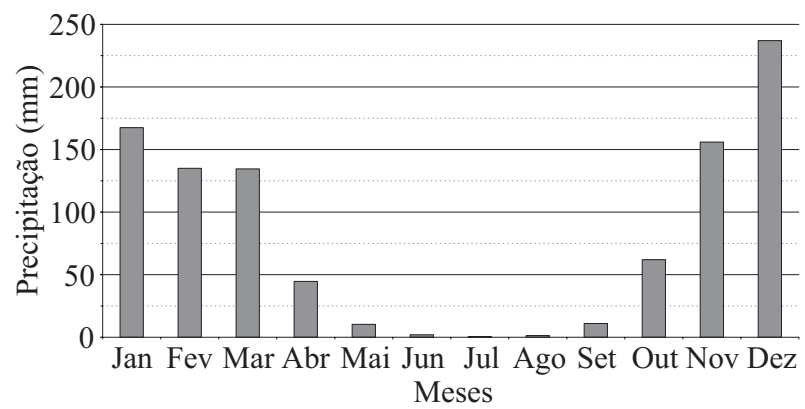

Figura 2 - Histograma da precipitação média mensal no período de 2000 a 2009, observados na estação meteorológica de Januária, Minas Gerais.

Figure 2 - Histogram of the average monthly rainfall from 2000 to 2009, observed in the Januária weather station, Minas Gerais state.

Em função dessas características climáticas, os incêndios nessa região são recorrentes, sempre nos períodos de baixa umidade relativa e baixa precipitação. Além desse fato, outro agravante está relacionado às questões culturais de uso da terra como, por exemplo, a prática de fogo para manejo da pastagem e preparo do solo para plantio de culturas agrícolas.

\subsection{Base de dados}

Foram utilizadas imagens do sensor TM a bordo do satélite LandSat 5, para mapear as áreas queimadas, por razões de disponibilidade e fácil acesso aos dados, além da sua ampla utilização no monitoramento da cobertura vegetal (LIU, 2007; PONZONI; SHIMABUKURO, 2007). Foram selecionadas duas imagens, uma de setembro e outra de outubro de 2008, obtidas junto à Divisão de Geração de Imagens - DGI do INPE, por meio do Catálogo Digital de Imagens Orbitais (INSTITUTO NACIONAL DE PESQUISAS ESPACIAIS - INPE, 2010). Para a escolha das imagens considerou-se a época crítica de ocorrência dos incêndios na região, bem como a ausência de nuvens nas imagens disponíveis. Na Tabela 1, apresenta-se a órbita/ponto e a data das imagens utilizadas neste trabalho.

Tabela 1 - Órbita ponto e data das imagens TM utilizadas nesse trabalho.

Table 1 - Path row and date of the TM images utilized in the research.

\begin{tabular}{cc}
\hline Órbita ponto & Data das imagens \\
\hline $219 / 70$ & $03 / 09 / 2008$ \\
$219 / 71$ & $03 / 09 / 2008$ \\
$219 / 70$ & $05 / 10 / 2008$ \\
$219 / 71$ & $05 / 10 / 2008$ \\
\hline
\end{tabular}

Os focos de calor utilizados compreendem o período de 03/09/2008 a 05/10/2008 e foram obtidos junto ao banco de dados de queimadas - BDQueimadas do INPE (2010). O download destes dados foi realizado no dia 01/02/2009.

Esses focos foram detectados a partir de métodos operacionais, desenvolvidos pelo INPE, que utilizam imagens de satélites meteorológicos de órbita polares da série NOAA, EOS (TERRA/AQUA - Sensor MODIS) e satélites de órbita geoestacionária GOES e METEOSAT. As características de resolução espacial, temporal e canal termal dos satélites utilizados nesse trabalho são apresentados na Tabela 2.

\subsection{Mapeamento das áreas queimadas}

O mapeamento das áreas queimadas foi realizado com base nas etapas propostas por Gato et al. (2001), na seguinte sequência: pré-processamento das imagens LandSat5 TM (registro, correção, mosaico, índice de vegetação NDVI T1 e T2 e imagem diferença dos NDVIs), segmentação e classificação semiautomática (crescimento de região), refinamento e vetorização (edição dos dados e exportação para ambiente de sistema de informação geográfica).

Cerne, Lavras, v. 18, n. 2, p. 335-343, abr./jun. 2012 
Tabela 2 - Características orbitais, espaciais* e temporais, e canal termal dos satélites utilizados no monitoramento das queimadas.

Table 2 -Orbital, spatial* and temporal characteristics, and thermal channel of the satellites utilized in fire monitoring.

\begin{tabular}{lcccc}
\hline Satélites & Órbita & Res. Espacial* & Resolução Temporal & Canal Termal \\
\hline AQUA/TERRA & Polar & $1,00 \times 1,00$ & $2 \times 2 /$ dia & $20(3,66-3,84 \mu \mathrm{m})$ \\
NOAAs & Polar & $1,10 \times 1,10$ & $2 \times 2 /$ dia & $3(3,55-3,93 \mu \mathrm{m})$ \\
GOES & Geoestacionária & $4,00 \times 4,00$ & $96 \times$ dia & $2(3,8-4 \mu \mathrm{m})$ \\
METEOSAT & Geoestacionária & $3,00 \times 3,00$ & $96 \times$ dia & $4(3,48-4,36 \mu \mathrm{m})$ \\
\hline
\end{tabular}

*Resolução espacial nominal em quilômetros no canal termal no nadir da imagem.

*Nominal spatial resolution in kilometers in the thermal channel at the image nadir.

Para fase de registro, foram coletados dez pontos de controle em cada imagem LandSat5 com a raiz do erro médio quadrático, ou RMSE, menor que um pixel. As correções geométricas foram feitas por meio do sistema de equações polinomiais de primeiro grau baseadas nesses pontos. Após essa correção, todas as imagens passaram a ter o mesmo sistema de coordenadas das imagens referência, ou seja, UTM WGS84.

Durante a fase de mosaico, utilizou-se o resultado da fase anterior e foram gerados dois mosaicos de imagens que cobriram totalmente a área de estudo, com um intervalo temporal de 32 dias, no período compreendido entre os dias 03/09/2008 e 05/09/2008.

$\mathrm{O}$ índice de vegetação escolhido foi o Normalized Difference Vegetation Índex - NDVI por ser amplamente utilizado na cartografia de áreas queimadas (BASTARRIKA; CHUVIECO, 2006), bem como na avaliação sazonal da vegetação (PONZONI; SHIMABUKURO, 2007), também em razão da sua simplicidade computacional (CARVALHO; SCOLFORO, 2006). Esse índice é uma normalização da resposta da vegetação, resultando num intervalo de -1 a 1 (ROUSE et al., 1973). Comparando as imagens NDVI antes e depois de um evento de queimada foi possível observar as mudanças na cobertura vegetal.

A imagem diferença, produto da subtração entre imagens NDVI T1 e T2, permite identificar os pixels onde não houve mudança com valor igual a 0 (zero). Por outro lado, nos locais onde ocorreu remoção da vegetação, os pixels terão seus valores próximos de 1 (um). Já, pixels com valores próximos de -1 (menos um) representam um crescimento da vegetação (CARVALHO; SCOLFORO, 2008).

A etapa de segmentação foi realizada de forma semiautomática, aplicando o algoritmo de crescimento de regiões na imagem diferença. Esse algoritmo avalia a similaridade das amostras coletadas pelo usuário em relação aos pixels vizinhos, segmentando aqueles com brilho similar (GATO et al., 2001).

Após a classificação das queimadas, os dados foram editados visando a corrigir possíveis erros por meio da interpretação visual, caracterizando assim a etapa de refinamento. As queimadas são facilmente interpretadas, em decorrência da sua cor e textura, principalmente quando se dispõe de imagens antes do incêndio (BASTARRIKA; CHUVIECO, 2006), o que facilita a correção (Figura 3). Por fim, a imagem classificada foi convertida para o formato vetorial onde os pixels adjacentes de mesma classe formaram um polígono.

\subsection{Quantificação das queimadas por classes de tamanho}

A quantificação das áreas afetadas foi baseada nas cicatrizes de queimadas, ou seja, nos polígonos resultantes do mapeamento por meio das imagens de satélite. Essas cicatrizes foram divididas em classes de tamanho, para permitir avaliar a influência do tamanho das queimadas e a detecção por meio de focos de calor. Na realidade, buscou-se compreender a influência do tamanho das áreas queimadas nas chances destas serem detectadas, em razão da baixa resolução espacial dos sensores utilizados e/ou pela baixa energia emitida nestes eventos.

As classes de tamanho de áreas queimadas são abordadas em diversos trabalhos, tais como os de Lima e Soares (2002), Medeiros e Fiedler (2003) e Ramsey e Higgins (1981). Para este trabalho, optou-se por um intervalo de classes considerando o tamanho nominal do pixel dos sensores, normalmente utilizados em trabalhos sobre monitoramento orbital de queimadas.

Foram definidas quatro classes de tamanho, nas quais os focos de calor enquadrados na classe I foram determinados empiricamente em função da resolução dos sensores utilizados (Tabela 3).

Cerne, Lavras, v. 18, n. 2, p. 335-343, abr./jun. 2012 
(a)

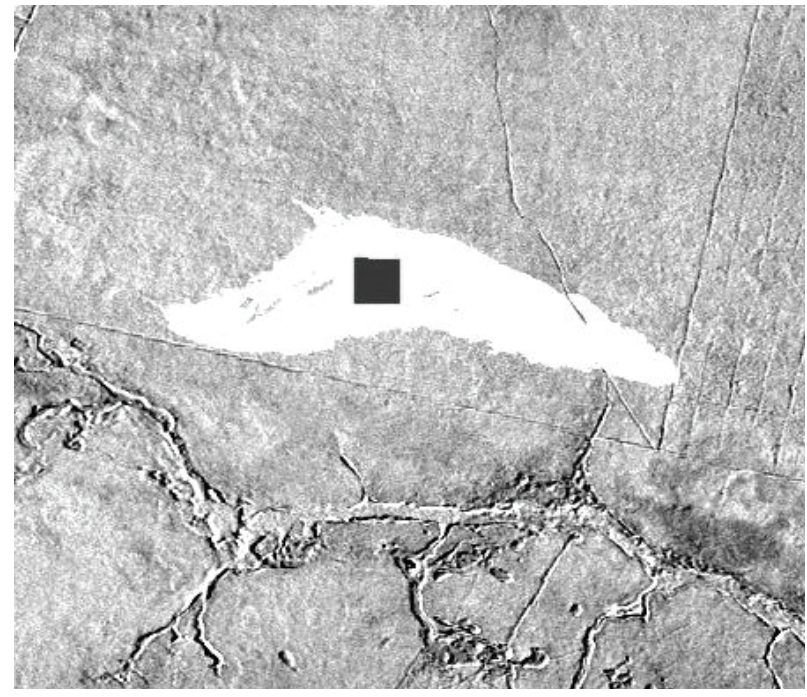

(b)

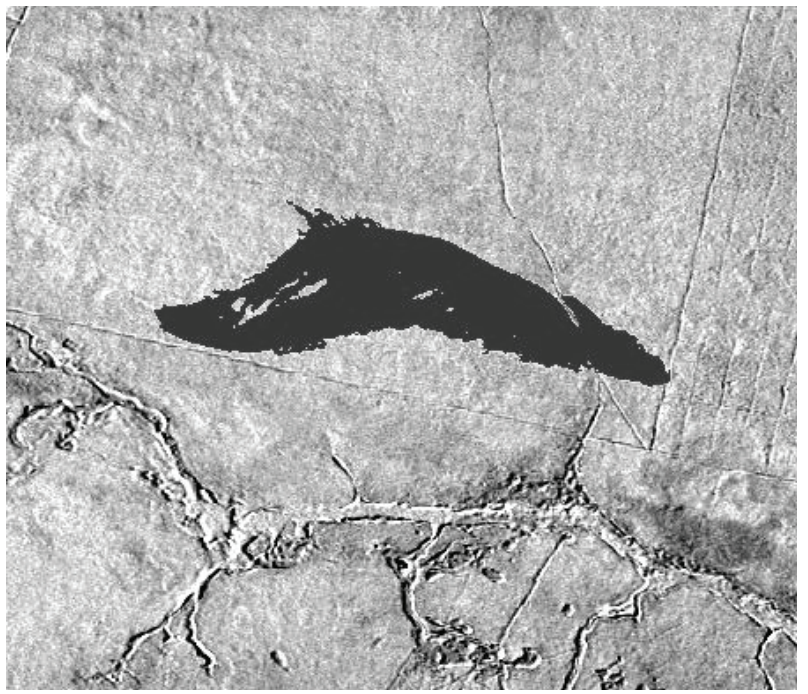

Figura 3 - Exemplo da amostra coletada a partir do recorte da imagem diferença (a) e após a execução do algoritmo de crescimento de região (b).

Figure 3 - Example of the sample collected from the difference image subset (a) and after the application of the region growth algorithm (b).

Tabela 3 - Classes de tamanho das queimadas para seis unidades de conservação no norte do estado de Minas Gerais.

Table 3 - Size classes of the burnt areas for six conservation units in the north of Minas Gerais State.

\begin{tabular}{cc}
\hline Classes & Área (ha) \\
\hline I & 0,00 a 25,00 \\
II & 25,10 a 100,00 \\
III & 100,00 a $1.600,00$ \\
IV & $>1.600,00$ \\
\hline
\end{tabular}

\subsection{Validação dos focos de calor}

Os dados de focos de calor foram analisados por meio da frequência de ocorrência na área de estudo durante o período dessa análise e foram representados pelas informações de frequência absoluta e frequência relativa $(\%)$.

De acordo com a detecção pelo monitoramento orbital, para considerar as queimadas ou incêndios mapeados como cicatrizes, deve haver focos de calor no interior das mesmas, bem como nas proximidades. Quando o foco está dentro da cicatriz, pode-se afirmar que esta foi detectada; por outro lado, quando observados focos apenas nas proximidades, essas foram analisadas por meio de interpretação visual. Para as situações em que cicatrizes apresentavam focos de calor dentro e em suas proximidades, verificou-se se esses focos correspondem realmente à mesma cicatriz, comparandose a data dos focos próximos com a dos focos dentro delas. Se semelhantes, foram consideradas como a mesma queimada.

Para a verificação dos possíveis erros de comissão, ou seja, aqueles cuja atribuição no mapa de determinada feição recai sobre uma classe a qual a mesma não pertence (falsos alarmes), analisaram-se os focos de calor com distância maior que 9,00 km de uma cicatriz mapeada. Em razão da baixa resolução espacial dos satélites utilizados para o monitoramento, esses focos podem ser registrados a grandes distâncias do local exato de ocorrência. $\mathrm{O}$ erro de um pixel pode representar 4,00 km no centro das imagens, sendo que, na borda, a tendência é aumentar esse erro. Portanto, considerou-se que os focos de calor com erro de comissão eram aqueles cujas distâncias foram maiores que $9,00 \mathrm{~km}$, sem a presença de outros focos em seus arredores, na mesma data e que foram considerados como acerto.

Para avaliar a localização dos focos de calor em relação às cicatrizes foi utilizado um conjunto de áreas de mesma distância no entorno das cicatrizes previamente mapeadas, ou seja, classes equidistantes com intervalos de $1,00 \mathrm{~km}$, criadas a partir de múltiplos "buffers" até a distância de $9,00 \mathrm{~km}$.

Cerne, Lavras, v. 18, n. 2, p. 335-343, abr./jun. 2012 
Posteriormente, por meio de uma consulta espacial, foi possível identificar em qual classe de distância cada foco estava contido, o que viabilizou integrar essa informação aos atributos obtidos, culminando no cálculo das estatísticas de cada classe de distância.

\section{RESULTADOS E DISCUSSÃO}

\subsection{Mapeamento e quantificação das queimadas por classe de tamanho}

Foram mapeadas 190 cicatrizes de queimadas da vegetação, perfazendo um montante de 18.771,00 ha. As menores queimadas corresponderam a uma área de 1,00 ha e a maior 2.324,00 ha. Com relação aos tamanhos, a maior frequência situou-se na classe I, que juntamente com a classe II, representaram $85,00 \%$ das cicatrizes mapeadas. É importante destacar que essas duas classes possuem extensões menores de 100,00 ha, representando dimensões menores que um pixel do sensor MODIS $(1,00$ $\mathrm{x} 1,00 \mathrm{~km}$ ) na banda termal. As frequências dos polígonos de cicatrizes de queimadas e áreas queimadas por classe de tamanho são apresentadas na Tabela 4.

As queimadas menores que 100,00 ha ocorreram com maior frequência na área estudada, no entanto, representaram apenas $18,00 \%$ do total das áreas queimadas. Os incêndios de grandes dimensões (classe III e IV), apesar da ocorrência em baixa frequência ( $15,00 \%$ das cicatrizes), representaram $82,00 \%$ do total de área queimada.

O sistema de monitoramento de queimadas detectou, aproximadamente, 63,00\% das queimadas maiores que 100,00 ha o que representa um erro de omissão, ou seja, a omissão no mapa de uma determinada feição constatada em campo, de aproximadamente $37,00 \%$, que seria esperado pela metodologia de detecção do INPE. Essas ocorrências representaram aproximadamente $71,00 \%$ do total de área queimada, demonstrando assim, resultados práticos satisfatórios. Dos 183 focos de calor analisados, aproximadamente $99,00 \%$ foram confirmados como acerto, mostrando que a informação dos focos de calor é confiável, ou seja, praticamente não existem falsos alarmes. No entanto, deve-se atentar para a limitação do método, uma vez que esses dados não foram coletados nas datas e nos locais das ocorrências. Para aperfeiçoamento, devem ser realizados trabalhos de campo a fim de aferir as informações obtidas.

\subsection{Validação dos focos de calor}

A quantidade de focos de calor proveniente de cada metodologia de detecção mostra que as diferenças espectrais, temporais e de limiares dos algoritmos, interferem no monitoramento efetivo de queima da vegetação. Na Tabela 5, apresentam-se as frequências absolutas e relativas para os focos de calor utilizados neste estudo.

Considerando todas as cicatrizes mapeadas, independente do tamanho, verificou-se que os focos de calor acertaram em $26,00 \%$ dos casos (dentro ou próximo das cicatrizes). As análises desses resultados levaram em consideração as limitações físicas, intrínsecas aos diferentes sistemas envolvidos, a fim de avaliar os acertos por classes de tamanho das queimadas (Tabela 6).

Das 30 queimadas maiores que 100,00 ha, aproximadamente $61,00 \%$ foram detectadas. O erro de omissão $(39,00 \%)$ está dentro do limite de aceitação adotado pela equipe do Sistema de Monitoramento de Queimadas do INPE.

Possivelmente, as grandes queimadas não detectadas devem-se a peculiaridades locais, tais como regiões onde ocorrem incêndios subterrâneos, dificultando ou impossibilitando o monitoramento orbital. Outra possível causa dos erros de omissão nesta classe de tamanho pode ser a ocorrência de queima em campo aberto

Tabela 4 - Queimadas mapeadas em seis unidades de conservação no norte do estado de Minas Gerais, no período de 03/09/2008 a 05/10/2008, separadas por classes de tamanho.

Table 4 - Mapped burnt areas in six conservation units in the north of Minas Gerais state in 03/09/2008 to 05/10/2008 period, separated by size classes.

\begin{tabular}{lcccc}
\hline Classes de tamanho & $\mathrm{N}^{\mathrm{o}}$ de polígonos & \% de polígonos & $\sum$ Área queimada (ha) & \% do total de área queimada \\
\hline$<25,00$ ha & 115 & 61,00 & 971,00 & 5,00 \\
25,01 a 100,00 ha & 45 & 24,00 & 2402,00 & 13,00 \\
100,01 a 1.600,00 ha & 28 & 14,00 & 11437,00 & 61,00 \\
$>1.600,00$ ha & 2 & 1,00 & 3961,00 & 21,00 \\
\hline Total & 190 & 100,00 & $18.771,00$ & 100,00 \\
\hline
\end{tabular}

Cerne, Lavras, v. 18, n. 2, p. 335-343, abr./jun. 2012 
Tabela 5 - Focos de calor detectados em seis unidades de conservação do norte do estado de Minas Gerais, no período de 03/09/2008 a 05/10/2008.

Table 5 - Hotspots detected in six conservation units in the north of Minas Gerais state, in 03/09/2008 to 05/10/2008 period.

\begin{tabular}{lcc}
\hline Focos & $\begin{array}{c}\text { Frequência } \\
\text { absoluta }\end{array}$ & $\begin{array}{c}\text { Frequência } \\
\text { relativa (\%) }\end{array}$ \\
\hline NOAA 18 & 4 & 2,00 \\
METEOSAT-02 & 5 & 3,00 \\
NOAA 16 & 5 & 3,00 \\
TERRA & 15 & 8,00 \\
GOES 10 & 15 & 8,00 \\
NOAA 15 & 31 & 17,00 \\
MMODIS-01D & 44 & 24,00 \\
AQUA & 64 & 35,00 \\
\hline Total & 183 & 100,00 \\
\hline
\end{tabular}

Tabela 6 - Total de ocorrências de queimadas, $\mathrm{n}^{\circ}$ de ocorrências detectadas por focos de calor e \% de ocorrências detectadas por classe de tamanho.

Table 6-Total of burnt areas occurrences, number of occurrences detected per hotspot and \% of occurrences detected per size class.

\begin{tabular}{lccc}
\hline $\begin{array}{l}\text { Classes de tamanho } \\
\text { de queimadas }\end{array}$ & $\begin{array}{c}\mathrm{N}^{\mathrm{o}} \\
\text { cicatrizes }\end{array}$ & $\begin{array}{c}\text { Cicatrizes com } \\
\text { focos de calor }\end{array}$ & $\begin{array}{c}\% \text { de } \\
\text { acerto }\end{array}$ \\
\hline $0,00-25,00$ ha & 115 & 18 & 16,00 \\
25,01 a 100,00 ha & 45 & 13 & 29,00 \\
100,01 a 1.600,00 ha & 28 & 17 & 61,00 \\
$>1.600,00$ ha & 2 & 2 & 100,00 \\
\hline Total & 190 & 50 & 26,00 \\
\hline
\end{tabular}

na presença de vento, o que resulta em uma grande área queimada em um pequeno intervalo de tempo, de tal modo que a passagem dos satélites não registra os focos de calor ativos. Por esses motivos, uma análise mais detalhada deve ser realizada com dados de campo, relatórios de incêndios, dados meteorológicos e novas análise dos valores dos pixels nas imagens em datas próximas às ocorrências.

As queimadas menores que 100,00 ha apresentaram uma omissão de 81,00 \%. Já, queimadas maiores que 100,00 ha tiveram uma omissão de aproximadamente $36 \%$. Martinez et al. (2007), estudando a relação entre focos de calor e desflorestamento, também verificaram que o tamanho dos desflorestamentos influenciam diretamente a omissão. A análise por classe de tamanho endossa a hipótese de que a alta frequência das cicatrizes na primeira classe é a principal causa da omissão dos focos, reflexo da baixa resolução espacial dos sensores utilizados.

Ao analisar a detecção do total de área queimada, pode-se verificar que o acerto total foi de $71,00 \%$, ou seja, dos 18.771,00 ha queimados, 13.399,00 ha tiveram a presença de focos de calor (Tabela 7).

Tabela 7 - Soma das áreas queimadas por classes de tamanho; das áreas queimadas detectadas (ha) com a presença de focos de calor e \% das áreas queimadas detectadas por focos de calor por classe de tamanho.

Table 7 - Total of the burnt areas per size classes; burnt areas detected (ha) with the presence of hotspots and \% of the detected burnt areas per hotspot.

\begin{tabular}{|c|c|c|c|}
\hline $\begin{array}{l}\text { Classes de tamanho } \\
\text { das queimadas }\end{array}$ & $\begin{array}{c}\Sigma \text { área } \\
\text { (ha) }\end{array}$ & $\begin{array}{c}\Sigma \text { da área queimada } \\
\text { e detectada (ha) } \\
\text { com presença de } \\
\text { focos de calor }\end{array}$ & $\begin{array}{l}\% \text { de } \\
\text { acerto }\end{array}$ \\
\hline $0,00-25,00$ ha & 971,00 & 240,00 & 25,00 \\
\hline 25,01 a 100,00 ha & $2.402,00$ & 733,00 & 30,00 \\
\hline 100,01 a $1.600,00$ ha & $11.437,00$ & $8.465,00$ & 74,00 \\
\hline$>1.600,00 \mathrm{ha}$ & $3.961,00$ & $3.961,00$ & 100,00 \\
\hline Total & $18.771,00$ & $13.399,00$ & 71,00 \\
\hline
\end{tabular}

Para chegar aos resultados apresentados (Tabela 7), foram somadas as áreas de todas as cicatrizes de cada classe de tamanho e, posteriormente, as áreas das cicatrizes nas quais se observaram focos de calor. Esses resultados comprovam que o monitoramento orbital de queimadas na vegetação por focos de calor é uma ferramenta que permite o planejamento das ações de prevenção e na atuação das brigadas de atendimento a emergências.

Quanto aos falsos alarmes, apenas dois focos AQUA estão relacionados a aproximadamente 1,00\% desses erros, não descartando a possibilidade de contribuição do erro de mapeamento na validação, em razão do longo intervalo de tempo (32 dias) entre a passagem do sensor e o mapeamento. Sabe-se que, em alguns casos, em poucos dias, a vegetação campestre se recompõe, interferindo na interpretação das imagens utilizadas como referência para o mapeamento das cicatrizes. Portanto, pode-se afirmar que 98,91\% dos focos de calor detectados fizeram referência a alguma cicatriz de queimada mapeada.

\subsubsection{Avaliação quanto à localização dos focos de calor}

A avaliação quanto à localização dos focos de calor foi realizada por meio da análise de frequência com que estes ocorreram nas classes de distância. Quanto maior a

Cerne, Lavras, v. 18, n. 2, p. 335-343, abr./jun. 2012 
frequência dos focos em classes de distâncias próximas, menor o grau de incerteza quanto à localização. A análise foi feita por focos de calor, avaliando a frequência com que esses eventos acontecem nas classes de distância (Tabela 8).

Tabela 8 - Frequência dos focos de calor por classes de distância, frequência relativa e frequência acumulada total.

Table 8 - Hotspots frequency per distance classes, relative frequency and total accumulated frequency.

\begin{tabular}{lccccccc}
\hline \multirow{2}{*}{ Focos de calor } & \multicolumn{7}{c}{ Classes de distância $(\mathrm{km})$} \\
\cline { 2 - 8 } & 0 & 1 & 2 & 3 & 4 & 8 & 9 \\
\hline AQUA & 18 & 33 & 9 & 2 & 0 & 1 & 1 \\
MMODIS-01D & 28 & 16 & 0 & 0 & 0 & 0 & 0 \\
TERRA & 3 & 6 & 4 & 1 & 1 & 0 & 0 \\
NOAA-15 & 1 & 8 & 9 & 11 & 2 & 0 & 0 \\
NOAA-16 & 0 & 1 & 1 & 0 & 0 & 2 & 1 \\
NOAA-18 & 0 & 2 & 2 & 0 & 0 & 0 & 0 \\
GOES-10 & 3 & 5 & 2 & 2 & 3 & 0 & 0 \\
METEOSAT-02 & 0 & 2 & 1 & 2 & 0 & 0 & 0 \\
\hline TOTAL & 53 & 73 & 28 & 18 & 6 & 3 & 2 \\
$\%$ relativa & 29 & 40 & 15 & 10 & 3 & 2 & 1 \\
$\%$ acumulada & 29 & 69 & 84 & 94 & 97 & 99 & 100 \\
\hline
\end{tabular}

Através dos dados apresentados na Tabela 8, podese verificar que, de maneira geral, $69,00 \%$ de todos os focos de calor estavam distantes em até $1,00 \mathrm{~km}$ das cicatrizes das queimadas, ou seja, uma distância que representa o tamanho do menor pixel de monitoramento, por exemplo, um pixel MODIS AQUA ou TERRA no nadir. Quase a totalidade, ou seja, $97,00 \%$ dos focos estavam a uma distância máxima de 4,00 km, o que representa um pixel GOES.

Quanto à localização, constatou-se que a maioria dos focos de calor está a uma distância máxima da dimensão de 1 pixel MODIS e NOAA, ou seja, 1,00 km. Os focos de calor com maior precisão são provenientes do produto MMODIS-01D e AQUA, o que é um indicativo para que as ações da base de monitoramento do Instituto Estadual de Florestas de Minas Gerais priorizem as coordenadas advindas desses produtos.

O produto MMODIS-01D foi o que apresentou melhor resultado, pois todos os focos desse produto estavam, no máximo, a $1,00 \mathrm{~km}$ de distância das cicatrizes de queimadas. Em seguida, os focos AQUA que ocorreram a uma distância máxima de 3,00 km. Esses resultados podem ser decorrentes do fato de estes sensores apresentarem menor resolução espacial entre os utilizados no monitoramento orbital de queimadas.

Vale lembrar, ainda, que essas dimensões correspondem aos pixels que se encontram no nadir e que, na borda das imagens, as distorções chegam a quatro vezes essas dimensões. Portanto, diante das limitações técnicas de resolução espacial, esses resultados podem ser considerados satisfatórios sob o ponto de vista de ações operacionais de movimentação dos recursos para combate às queimadas $\mathrm{e}$, sob o ponto de vista de monitoramento, $\mathrm{o}$ resultado pode ser considerado muito bom.

\section{CONCLUSÕES}

As queimadas de menores dimensões são menos passíveis de detecção orbital.

A alta frequência das cicatrizes de queimadas nas duas primeiras classes de tamanho, explicam o alto índice de omissão dos focos de calor, os quais se encontram dentro dos limites definidos pelo Sistema de Monitoramento de Queimadas do INPE.

A frequência dos focos de calor mostrou que as diferenças espectrais, temporais e de limiares dos algoritmos, interferem no monitoramento de queima da vegetação, que pressupõe uma quantidade maior de satélites, ampliando a cobertura de informações.

Os focos de calor com maior precisão foram provenientes do produto MMODIS-01D e AQUA, podendo direcionar as ações do órgão responsável pelo monitoramento.

Ferramentas da geotecnologia para validação dos focos de calor se mostraram eficientes. Novos estudos devem ser desenvolvidos para aprimorar os casos de omissão e comissão.

\section{AGRADECIMENTOS}

Ao Instituto Nacional de Pesquisas Espaciais (INPE) e ao Instituto Estadual de Florestas pela base de dados, à Universidade Federal de Lavras - Laboratório de Manejo Florestal (LEMAF) pelo apoio logístico e a Conselho Nacional de Desenvolvimento Científico e Tecnológico (CNPq) pelo apoio financeiro durante o desenvolvimento deste trabalho.

\section{REFERÊNCIAS}

BASTARRIKA, A. Y.; CHUVIECO, E. Cartografía del área quemada mediante crecimiento de regiones: aplicación en entornos mediterráneos con imágenes TM y ETM+.

GeoFocus, Jacupiranga, v. 6, p. 182-204, out. 2006.

Cerne, Lavras, v. 18, n. 2, p. 335-343, abr./jun. 2012 
CARVALHO, L. M. T.; SCOLFORO, J. R. S. Inventario florestal de Minas Gerais: monitoramento da flora nativa 2005-2007. Lavras: UFLA, 2008. 318 p.

CARVAlHO, L. M. T.; SCOLFORO, J. R. S. Mapeamento e inventário da flora nativa e dos reflorestamentos de Minas Gerais. Lavras: UFLA, 2006. 288 p.

DEEP, F.; PAULA, E. V. FIRESIG sistema de suporte a tomada de decisão para o combate a incêndios no Paraná. Revista Floresta, Curitiba, v. 34, n. 2, p. 157-162, maio/ago. 2004.

GATO, H. E. R.; IMAI, N. N.; TOMMASELLI, A. M. G. Uma abordagem semi-automática para extração de feições cartográficas. Revista Brasileira de Cartografia, Rio de Janeiro, v. 53, p. 16-28, dez. 2001.

\section{INSTITUTO BRASILEIRO DE GEOGRAFIA E} ESTATÍSTICA. Mapa de biomas do Brasil. Rio de Janeiro, 2004. Escala 1:5.000.000. Disponível em: $<$ http:// mapas.ibge.gov.br/biomas2/viewer.html>. Acesso em: 15 jun. 2009.

\section{INSTITUTO DE GEOCIÊNCIA APLICADA. Áreas} de proteção ambiental no Estado de Minas Gerais: demarcação e estudos para o pré-zoneamento ecológico. Belo Horizonte: APA Bacia do Rio Pandeiros, 2006. 271 p.

INSTITUTO NACIONAL DE PESQUISAS ESPACIAIS. Catálogo de imagens. Disponível em: <http://www.dgi.inpe. br/CDSR>. Acesso em: 10 out. 2010.

\section{INSTITUTO NACIONAL DE PESQUISAS ESPACIAIS.}

Queimadas: monitoramento de focos. Disponível em: $<$ http:// www.dpi.inpe.br/proarco/bdqueimadas $>$. Acesso em: 5 out. 2010.

KÖPPEN, W. Das geographische system der klimate. In: Handbuch der klimatologie. Berlin: [s.n.], 1936. $240 \mathrm{p}$.

LIMA, G. S.; SOARES, R. V. Avaliação da eficiência de combate aos incêndios florestais no Brasil. Revista Floresta, Curitiba, v. 22, n. 1/2, p. 25-38, jul. 2002.

LIU, W. T. H. Aplicações de sensoriamento remoto. Campo Grande: UNIDERP, 2007. 908 p.
MARTINEZ, L. L.; FIEDLER, N. C.; LUCATELLI, G. J. Análise das relações entre desflorestamentos e focos de calor: estudo de caso nos municípios de Altamira e São Félix do Xingu, no estado do Pará. Revista Árvore, Viçosa, v. 31, n. 4, p. 695-702, jul./ago. 2007.

MEDEIROS, M. B.; FIEDLER, N. C. Incêndios florestais no parque da Serra da Canastra: desafios para a conservação da biodiversidade. Ciência Florestal, Santa Maria, v. 14, n. 2, p. 157-168, mar./abr. 2003.

MORISETTE, J. T.; KHORRAM, S. Accuracy assessment curves for satellite-based change detection. Photogrammetric Engineering and Remote Sensing, Falls Church, v. 66, n. 7, p. 876-880, July 2000.

PEREIRA, A. A.; PEREIRA, L. C.; VALADARES, R. Monitoramento dos incêndios florestais no estado de Minas Gerais. In: SIMPÓSIO BRASILEIRO DE SENSORIAMENTO REMOTO, 13., 2007, Florianópolis. Anais... Florianópolis: INPE, 2007. p. 4535-4540.

PHULPIN, T.; LAVENU, F.; BELLAN, M. F.; MOUGENOT, B.; BLASCO, F. Using SPOT-4 HRVIR and vegetation sensors to assess impact of tropical forest fires in Roraima, Brazil. International Journal of Remote Sensing, Basingstoke, v. 23, n. 10, p. 1943-1966, Oct. 2002.

PONZONI, F. J.; SHIMABUKURO, Y. E. Sensoriamento remoto aplicado ao estudo da vegetação. São José dos Campos: Parêntese, 2007. v. 1, 135 p.

RAMSEY, G. S.; HIGGINS, D. G. Canadian forest fire statistic. Ontario: Canadian Forestry Service, 1981. 315 p. (Information Report, 71).

ROUSE, J. W.; SCHELL, J. A.; DEERING, D. W. Monitoring vegetation systems in the great plains with ERTS. In: NASA ERTS SYMPOSIUM, 3., 1973, Washington. Proceedings... Washington: NASA, 1973. p. 309.

XAUD, M. R.; SILVA, G. F. N.; XAUD, H. A. M.; BARBOSA, R. J.; ESBELL, D.; COSTA, V. P. Monitoramento de queimadas e incêndios florestais em Roraima: informações orbitais e locais subsidiando tomadas de decisão. In: SIMPÓSIO BRASILEIRO DE SENSORIAMENTO REMOTO, 13., 2003, Belo Horizonte. Anais... Belo Horizonte: INPE, 2003. p. 533-534.

Cerne, Lavras, v. 18, n. 2, p. 335-343, abr./jun. 2012 